\title{
Physical activity, genes, and lifetime predisposition to chronic disease
}

\author{
Urho M. Kujala
}

Received: 3 August 2010 / Accepted: 15 December 2010/Published online: 5 January 2011

(C) European Group for Research into Elderly and Physical Activity (EGREPA) 2010

\begin{abstract}
This mini-review summarizes the main associations between physical activity and chronic diseases and discusses the basic concepts related to the role of genetic factors in studies evaluating the effects of physical activity/exercise therapy on chronic disease prevention/ treatment during the life course. Many observational cohort studies have shown that high physical activity during young adulthood or middle age is associated with reduced later life morbidity, mobility limitations and mortality. Physical activity or exercise therapy has a positive effect on health via many disease-specific mechanisms. The most consistent finding of the various randomized controlled studies conducted to date is that aerobic/functional capacity and/or muscle strength can be improved by exercise training among patients with different chronic diseases. Genes are known to play a role in chronic disease predisposition and to contribute to physical fitness levels, physical activity participation and ageing. Physical fitness, physical activity and health outcomes may be partly due to underlying genetic factors that have a favourable effect on all these traits (genetic pleiotropy). This means that in observational studies, the relationship between baseline activity and the later occurrence of diseases may not be interpreted entirely as causal. Increased knowledge on the role of nuclear genome, mitochondrial genome, epigenetics, telomeres and regulation of gene expression will increase our
\end{abstract}

U. M. Kujala $(\bowtie)$

Department of Health Sciences, Sports and Health Laboratory,

Rautpohjankatu 8, University of Jyväskylä,

P.O. Box 35 (LL), FIN-40014 Jyväskylä, Finland

e-mail: urho.m.kujala@jyu.fi understanding of their relationships with physical activity and morbidity.

Keywords Physical activity - Chronic disease - Genes . Heritability · Ageing

\section{Introduction}

During the past few decades, much evidence has accumulated on the associations between physical activity/exercise and the occurrence of chronic diseases. Recently, our understanding on the interplay between physical activity, genes and health has also significantly increased. This minireview summarizes the main associations between physical activity and chronic diseases and discusses the basic concepts related to the role of genetic factors in studies evaluating the effects of physical activity/exercise therapy on chronic disease prevention/treatment during the life course.

\section{Health effects of physical activity throughout the life course}

Different studies investigating the relationships between physical activity/exercise and health have specific strengths and weaknesses according to their design (Table 1). For clinical purposes, we usually need to consider evidence from different types of studies. Evidence from observational follow-up studies is usually sufficient to give general advice to people to prevent chronic disease, but evidence from randomized controlled trials is a priority when using the resources of health care to rehabilitate individuals with specific chronic diseases [1]. 
Table 1 Strengths and weaknesses of the study designs in physical activity/exercise and health research

\begin{tabular}{lll}
\hline Study design & Strengths & Weaknesses \\
\hline Observational cohort studies & $\begin{array}{l}\text { Large sample sizes } \\
\text { Population-based samples } \\
\text { Long follow-ups }\end{array}$ & Unclear cause-and-effect evaluation \\
& Healthy exerciser bias \\
Experimental mechanistic studies & Show in-detail effects of training on specific risk factors & Small sample sizes \\
& & $\begin{array}{c}\text { Effects on true disease outcomes and disease } \\
\text { progression unclear }\end{array}$ \\
(Randomized) controlled trials & Reliable evaluation of cause-and-effect & $\begin{array}{l}\text { Small sample sizes } \\
\text { Short follow-ups }\end{array}$ \\
\hline
\end{tabular}

Childhood and adolescence

As many common chronic diseases related to sedentary lifestyles usually occur later in life, finding out how physical activity during childhood protects against chronic disease is problematic. Very long-term RCTs are not available, and longitudinal observational studies have known limitations, such as problems related to the evaluation of causality and controlling for different confounding factors. Thus, the majority of studies have only focused on the role of exercise in the development of cardiovascular, musculoskeletal and psychological risk factors. The normal growth-related changes make this research challenging. However, some important findings have been made among children and adolescents, which may have a significant role in the prevention of diseases and disability in later life, in particular when physical activity persists from childhood to adulthood. First, there is no doubt that exercise training increases muscular strength as well as aerobic fitness in children [2]. Although increasing the physical activity of normalweight youth usually has rather small effects on weight gain, RCTs have shown that physical activity decreases total body and visceral fatness, at least in obese children $[3,4]$. Fatness is associated with unfavourable cardiovascular risk factors [5]. Further, childhood has been shown to be an important period when bone development can be influenced by physical activity. Bone-loading physical activity increases bone mineral content and density [6-8]. There is also some evidence that physical activity may decrease depression [9, 10].

Adults and older people

Among adults, many observational cohort studies have shown that high physical activity in young adulthood or middle age is associated with reduced occurrence of chronic disease, limitations in daily functioning and deaths in later life. For many chronic diseases, there is a dose- response relationship, suggesting causality between high physical activity and low morbidity and mortality [11]. Physical activity or exercise therapy can have a positive effect on health via many disease-specific mechanisms (Fig. 1).

The most consistent finding of the various randomized controlled trials conducted to date is that aerobic/functional capacity and/or muscle strength can be improved by exercise training among patients with different chronic diseases [1]. This is important as the proportion of older people is increasing and exercise therapy may be an important means to reduce disability and increase the numbers of those able to live independently in the community. The finding that aerobic exercise training consistently increases physical performance capacity and maximal oxygen uptake in patients with chronic diseases is important as observational studies have shown that low aerobic fitness is an important risk factor for mortality in this population segment [12], as it has been shown among apparently healthy people [11].

Besides fitness, other cardio-metabolic risk factors have also been found to improve during exercise therapy trials among high-risk or chronically ill individuals. Of particular importance is the finding from randomized controlled trials showing that exercise reduces visceral fat [13]. This is found even in the absence of changes in total body weight, as skeletal muscle mass often increases as a consequence of exercise training.

When compared to pharmacological therapy, exercise usually has positive effects via many different mechanisms (Fig. 1), although pharmacological treatment targeted at a specific parameter may have an effect size as high, if not higher. The possible overall strong health benefit of exercise therapy in the prevention and treatment of a disease seems to be the sum effect of long-term exercise mediated via different mechanisms.

There is limited evidence from very long-term follow-up studies on the associations between baseline physical activity at a young age and health in later life. One 
Fig. 1 Mechanisms via which physical activity has beneficial effects on health. Modified from Kujala [1]

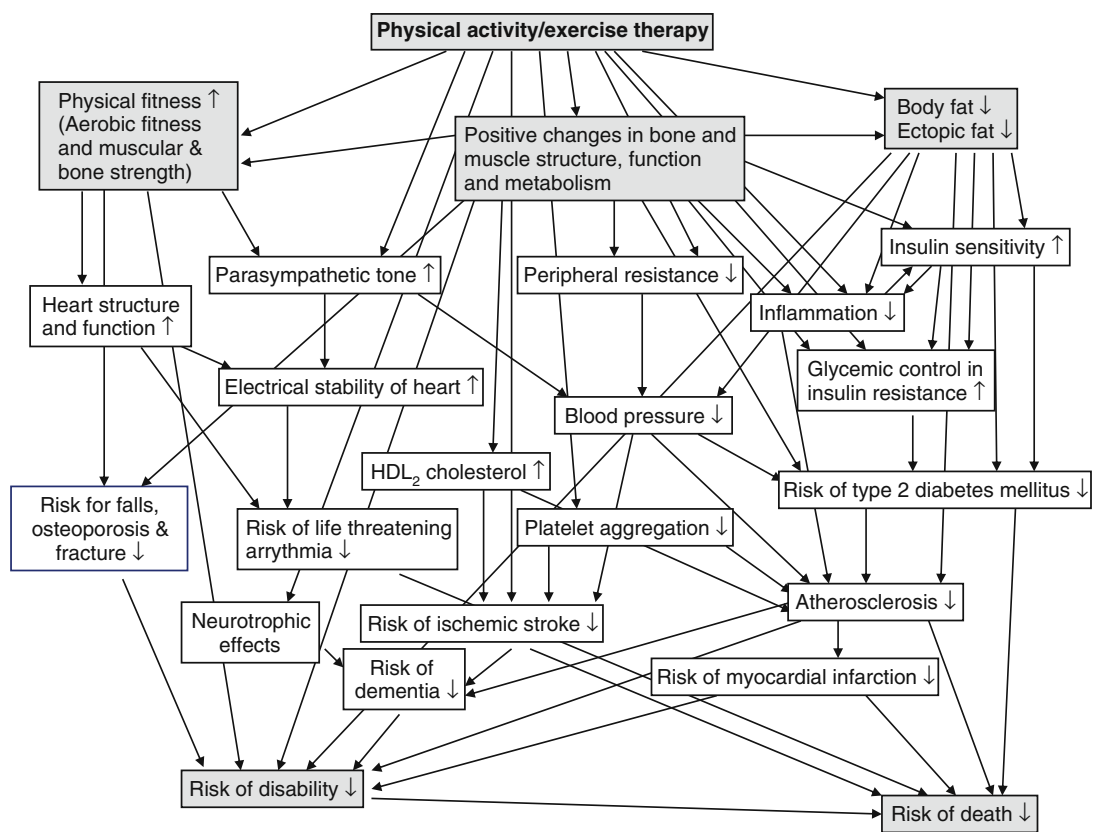

exception is the study on Finnish former elite athletes (with a maximum follow-up time of 90 years) which has shown that both participation in endurance sports as young adult and later physical activity independently predict lower morbidity in the later years of life (for a review see Kujala et al. [14]). These athletes had lower need of hospital care in later life compared to controls who were in good health at a younger age. Also, the need of hospital care during the last year of life was reduced among those with a high physical activity level in middle age [15]. As all observational population follow-ups, this study also may include a genetic selection bias (the same genetic factors may predispose individuals to high fitness and low risk of chronic disease; for more details, see later) although the documentation on the long-term exercise history of former athletes can be regarded as rather reliable. One way, at least in part, to tackle the genetic selection bias in long-term studies is to investigate twin pairs discordant for physical activity. For example, one such study with a 28 -year follow-up found evidence for the long-term benefits of physical activity vs. inactivity in the prevention or delaying of type 2 diabetes onset [16].

Among older people, in addition to preventing chronic diseases, the effects of physical activity on daily function become increasingly important (see von Bonsdorff and Rantanen in this issue). It has been shown that physical activity has an important role in the prevention of sarcopenia and osteopenia and in increasing maximal oxygen uptake, muscle strength, and balance in older people. To gain all these benefits, different types of training including aerobic, strength and balance training are recommended for older people [17]. Interestingly, evidence is also accumulating from both human and animal experiments to support the notion that physical activity is associated with improved cognitive function and that exercise training can improve many aspects of cognitive function [18]. On the one hand, RCTs with older people suggest that physical activity has beneficial effects among people with neurodegenerative disease [19] and depression [20]. Some animal experiments in turn show that it is likely that exerciseinduced molecular and cellular changes explain improvements in cognitive function [18].

\section{Heritability and genetic selection in modifying relationships between physical activity and chronic diseases}

Genes are known to play a role in chronic disease predisposition as well as contribute to physical fitness levels, physical activity participation and ageing. DNA sequence-level differences have been thought to be responsible for constant predisposition to chronic diseases and physical activity during life course. However, it is now known that the influence of the same sequence-level genetic variants on phenotype may differ by environment and by age. Gene-exercise interaction refers to a situation where the response or the adaptation to exercise is conditional on the individual's genotype. Also, studies in epigenetics suggest that changes in gene expression caused by mechanisms other than changes in the underlying DNA sequence may be inherited [21]. These changes may remain through cell divisions and thus may be transferred down to succeeding generations. The term 'epigenetics' does not 
have a simple uniform determination, but can be described as the structural adaptations of chromosomal regions so as to register, signal or perpetuate altered activity states [21]. An interesting new area of research is telomeres, which are DNA-protein complexes capping chromosomal ends. At cellular divisions, telomeres tend to shorten if not properly counteracted by telomerase. Further, shortening of telomeres seems to be associated with biological 'ageing' phenomena. Telomere shortening may be associated with physical inactivity and chronic diseases [22].

Genetic influences play an important role in explaining individual differences in exercise participation and leisure time physical activity [23-25]. However, knowledge on the genes and DNA sequence variants that contribute to the genetic variance in physical activity or physical fitness is scarce $[26,27]$.

Pleiotropy occurs when a single gene influences more than one phenotypic trait at the same time. The mechanism may be that the gene codes for a product that is, for example, used by various cells, or has a signaling function with respect to various targets. Regular exercise behavior and health outcomes may be partly due to underlying genetic factors that have a favourable effect on both traits $[14,28,29]$. This explains why some of the associations between baseline physical activity and future occurrence of disease seen in observational studies may be due to genetic pleiotropy (see Fig. 2). Some studies have tried to tackle this problem in a longitudinal design by observing the associations between changes in physical activity and future health. However, this design is also problematic as individuals in undiagnosed predisease states may reduce their activity, while healthy ones embark on vigorous activity. Physical activity may also have an effect on the associations between genetic polymorphisms and phenotypes: for example, there is accumulating evidence in that increased physical activity reduces the genetic variance of some cardio-metabolic risk factors [30-34]. This phenomenon is clarified in Fig. 3. The attenuation of genetic predisposition to cardio-metabolic risk by physical activity is good news for high-risk individuals. In addition, our understanding on the factors related to gene expression, including the whole pathway from DNA sequence to proteins is increasing rapidly; this in turn will increase understanding of the interplay between genes, physical activity and health, and of the possible changing role during the life course of the effects and meaning of different genetic variations.

Most of the genetic studies so far have focused on genes encoded by the nuclear genome. We need more large-scale studies on common and uncommon nuclear genome variants associated with both physical activity and chronic diseases, but also studies on mitochondrial genes as they may be related to aerobic fitness and metabolic disease development [35].

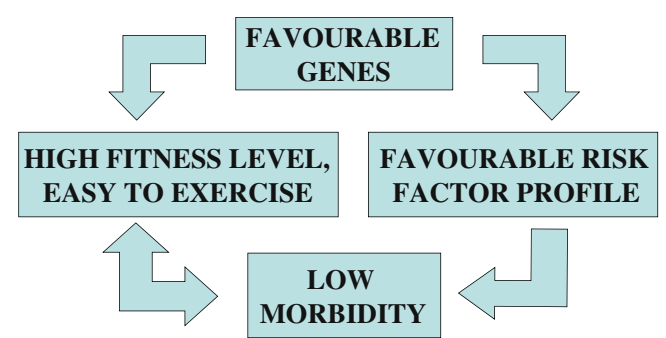

Fig. 2 A simplified diagram showing how genetic pleiotropy may have an effect on the physical activity-morbidity relationship. This means that in observational studies the relationship between baseline activity and later occurrence of diseases may not be interpreted entirely as causal

Not only the level of physical activity or cardio-metabolic risk factor levels but also responsiveness to exercise training is regulated by genes. Among other variables, this has been shown for physical fitness [36] and insulin sensitivity [37]. In future, understanding the biological basis of variation in responsiveness to exercise may help us to tailor optimal individualized prevention and treatment strategies. The first findings on molecular predictors of responsiveness to exercise training have already been published [38].

\section{Conclusions and future challenges}

A phenotype characterized by high physical activity and high aerobic fitness is a strong predictor of low cardiometabolic morbidity and mortality. This is a result of complex molecular networks responding to genetic and environmental factors during the life course [39]. Our understanding of genetics, the effects of exercise and their interactions is accumulating rapidly. In addition to clarifying these relationships using different modern approaches,

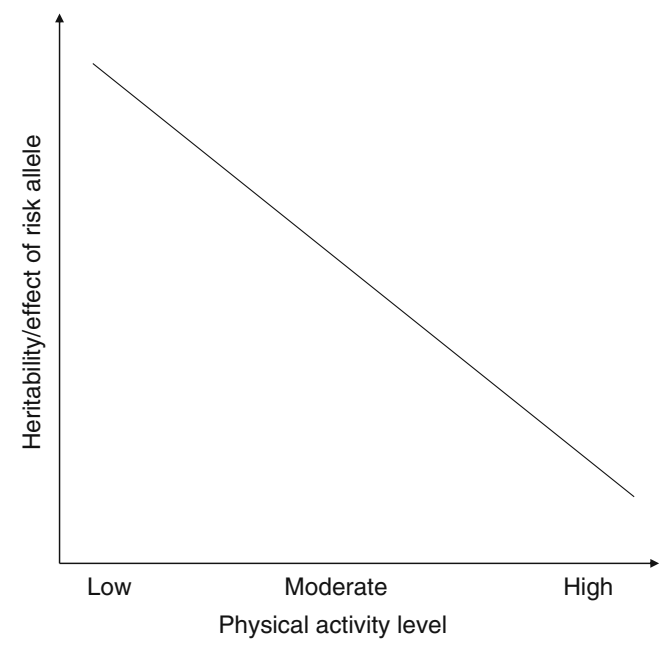

Fig. 3 Some evidence from studies on the interactions between metabolic disease risk genes and physical activity show that the effect of the risk allele is attenuated among physically active subjects (see text) 
there is a continuous need to carry out large-scale long-term randomized controlled trials testing the effects of exercise on different outcomes. Differences in the determinants and potential to respond to exercise training by age should also be studied more. Overall, a life-long physically active lifestyle seems to bestow the highest health benefits.

\section{References}

1. Kujala UM (2009) Evidence of the effects of exercise therapy in the treatment of chronic disease. Br J Sports Med 43:550 555

2. Baquet G, van Praagh E, Berthoin S (2003) Endurance training and aerobic fitness in young people. Sports Med 33:1127-1143

3. Owens S, Gutin B, Allison J, Riggs S, Ferguson M, Litaker M et al (1999) Effect of physical training on total and visceral fat in obese children. Med Sci Sports Exerc 31:143-148

4. Barbeau P, Johnson MH, Howe CA, Allison J, Davis CL, Gutin B et al (2007) Ten months of exercise improves general and visceral adiposity, bone, and fitness in black girls. Obesity (Silver Spring) 15:2077-2085

5. Gutin B, Johnson MH, Humphries MC, Hatfield-Laube JL, Kapuku GK, Allison JD et al (2007) Relationship of visceral adiposity to cardiovascular disease risk factors in black and white teens. Obesity (Silver Spring) 15:1029-1035

6. Morris FL, Naughton GA, Gibbs JL, Carlson JS, Wark JD (1997) Prospective ten-month exercise intervention in premenarcheal girls: positive effects on bone and lean mass. J Bone Miner Res 12:1453-1462

7. Heaney RP, Abrams S, Dawson-Hughes B, Looker A, Marcus R, Matkovic V et al (2000) Peak bone mass. Osteoporos Int 11:9851009

8. MacKelvie KJ, Petit MA, Khan KM, Beck TJ, McKay HA (2004) Bone mass and structure are enhanced following a 2-year randomized controlled trial of exercise in prepubertal boys. Bone 34:755-764

9. Crews DJ, Lochbaum MR, Landers DM (2004) Aerobic physical activity effects on psychological well-being in low-income Hispanic children. Percept Mot Skills 98:319-324

10. Annesi JJ (2005) Correlations of depression and total mood disturbance with physical activity and self-concept in preadolescents enrolled in an after-school exercise program. Psychol Rep 96:891-898

11. Physical Activity Guidelines Advisory Committee (2008) Physical activity guidelines advisory committee report, 2008. US Department of Health and Human Services, Washington

12. Myers J, Prakash M, Froelicher V, Do D, Partington S, Atwood JE (2002) Exercise capacity and mortality among men referred for exercise testing. N Engl J Med 346:793-801

13. Ohkawara K, Tanaka S, Miyachi M, Ishikawa-Takata K, Tabata I (2007) A dose-response relation between aerobic exercise and visceral fat reduction: systematic review of clinical trials. Int $\mathbf{J}$ Obes 31:1786-1797

14. Kujala UM, Marti P, Kaprio J, Hernelahti M, Tikkanen H, Sarna S (2003) Occurrence of chronic disease in former top-level athletes. Predominance of benefits, risks or selection effects? Sports Med 33:553-561

15. Kujala UM, Sarna S, Kaprio J, Koskenvuo M (2006) Hospital care in later life among former world-class Finnish athletes. JAMA 276:216-220

16. Waller K, Lehtovirta M, Kaprio J, Silventoinen K, Koskenvuo M, Kujala UM (2010) Physical activity in the prevention of type 2 diabetes; a 28-year follow up study in twins. Diabetologia 53:2531-2537

17. American College of Sports Medicine (2009) Exercise and physical activity for older adults. Med Sci Sports Exerc 41:1510-1530

18. Hillman CH, Erickson KI, Kramer AF (2008) Be smart, exercise your heart: exercise effects on brain and cognition. Nat Neurosci Rev 9:58-65

19. Heyn P, Abreu BC, Ottenbacher KJ (2004) The effects of exercise training on elderly persons with cognitive impairment and dementia: a meta-analysis. Arch Phys Med Rehabil 85:1694-1704

20. Mead GE, Morley W, Campbell P, Greig CA, McMurdo M, Lawlor DA (2008) Exercise for depression. Cochrane Database Syst Rev 2008(4):CD004366

21. Bird A (2007) Perceptions of epigenetics. Nature 447:396-398

22. Puterman E, Lin J, Blackburn E, O'Donovan A, Adler N, Epel E (2010) The power of exercise: buffering the effect of chronic stress on telomere length. PLoS ONE 5:e10837

23. Kaprio J, Koskenvuo M, Sarna S (1981) Cigarette smoking, use of alcohol, and leisure-time physical activity among same-sexed adult male twins. Prog Clin Biol Res 69:37-46

24. Beunen G, Thomis M (1999) Genetic determinants of sports participation and daily physical activity. Int J Obes Rel Metab Disord 23:55-63

25. Stubbe JH, Boomsma DI, Vink JM, Cornes BK, Martin NG et al (2006) Genetic influences on exercise participation in 37.051 twin pairs from seven countries. PLoS ONE 20:e22

26. De Moor MH, Liu YJ, Boomsma DI, Li J, Hamilton JJ, Hottenga $\mathrm{JJ}$ et al (2009) Genome-wide association study of exercise behavior in Dutch and American adults. Med Sci Sports Exerc 41:1887-1895

27. Rankinen T, Roth SM, Bray MS, Loos R, Perusse L, Wolfarth B et al (2010) Advances in exercise, fitness, and performance genomics. Med Sci Sports Exerc 42:835-846

28. Kujala UM, Kaprio J, Koskenvuo M (2002) Modifiable risk factors as predictors of all-cause mortality: the roles of genetics and childhood environment. Am J Epidemiol 156:985-993

29. de Geus EJC, de Moor MHM (2008) A genetic perspective on the association between exercise and mental health. Ment Health Phys Activ 1:53-61

30. Andreasen $\mathrm{CH}$, Stender-Petersen KL, Mogensen MS, Terekov SS, Wegner L, Andersen G et al (2008) Low physical activity accentuates the effect of the FTO rs9939609 polymorphism on body fat accumulation. Diabetes 57:95-101

31. Kilpeläinen TO, Lakka TA, Laaksonen DE, Lindström J, Eriksson JG, Valle TT et al (2008) SNPs in PPARG associate with type 2 diabetes and interact with physical activity. Med Sci Sports Exerc 40:25-33

32. Mustelin L, Silventoinen K, Pietiläinen K, Rissanen A, Kaprio J (2009) Physical activity reduces the influence of genetic effects on BMI and waist circumference: a study in young adult twins. Int $\mathrm{J}$ Obes 33:29-36

33. McCaffery JM, Papandonatos GD, Bond DS, Lyons MJ, Wing RR (2009) Gene $\times$ environment interaction of vigorous exercise and body mass index among male Vietnam-era twins. Am J Clin Nutr 89:1011-1018

34. Li S, Zhao JH, Luan J, Ekelund U, Luben RN, Khaw K-T et al (2010) Physical activity attenuates the genetic predisposition to obesity in 20, 000 men and women from EPIC-Norfolk prospective population study. PLoS Med 7(8):e1000332

35. Scott RA, Fuku N, Onywera VO, Boit M, Wilson RH, Tanaka $M$ et al (2009) Mitochondrial haplogroups associated with elite Kenyan athlete status. Med Sci Sports Exerc 41:123128 
36. Bouchard C, Rankinen T (2001) Individual differences in response to regular physical activity. Med Sci Sports Exerc 33: S446-S451

37. Boule NG, Weisnagel SJ, Lakka TA, Tremblay A, Bergman RN, Rankinen $\mathrm{T}$ et al (2005) Effects of exercise training on glucose homeostasis. Diab Care 28:120-126

38. Timmons JA, Knudsen S, Rankinen T, Koch LG, Sarzynski $M$, Jensen $T$ et al (2010) Using molecular classification to predict gains in maximal aerobic capacity following endurance exercise training in humans. J Appl Physiol 108:14871496

39. Leskinen T, Rinnankoski-Tuikka R, Rintala M, Seppänen-Laakso T, Pöllänen E, Alen M et al (2010) Differences in muscle and adipose tissue gene expression and cardio-metabolic risk factors in the members of physical activity discordant twin pairs. PLoS ONE 5(9):e12609 